\title{
Reflexões de professores de inglês em formação sobre o uso de Webquests Interativas e Adaptáveis no processo de ensino e aprendizagem da língua inglesa ${ }^{1}$
} Reflections by future language teachers in the use of Interactive and Adaptable Webquests in the process of teaching and learning English

\author{
Camila Gonçalves dos Santos do Canto*2 \\ Universidade Federal do Pampa \\ Jaguarão, Rio Grande do Sul / Brasil.
}

\begin{abstract}
RESUMO: O presente estudo, de cunho qualitativo, é um recorte da tese de doutorado da autora a qual propôs um novo modelo de Webquest voltado ao ensino de línguas por meio de um sistema interativo de autoria - a ferramenta Elo Cloud. Os resultados aqui apresentados voltam-se ao papel reflexivo de futuros professores de língua inglesa quanto ao uso das Webquests Interativas e Adaptáveis nas práticas de ensino e aprendizagem de línguas. As reflexões feitas a partir da fala dos professores em formação demonstraram que as Webquests Interativas e Adaptáveis são potencializadoras no processo de aprendizagem de línguas por fornecerem conteúdos interativos e dinâmicos que focam no aprendizado da língua inglesa.
\end{abstract}

PALAVRAS-CHAVE: webquest; professores; ensino de línguas.

* camilagds@gmail.com

${ }^{1} \mathrm{O}$ trabalho apresenta um recorte dos resultados da tese de doutorado de Camila Gonçalves dos Santos do Canto, a qual foi desenvolvida sob orientação do Dr. Vilson José Leffa, professor no Programa de Pós-Graduação em Letras (PPGL) da Universidade Católica de Pelotas (UCPEL).

2 Professora do curso de Licenciatura em Letras Português modalidade a distância da Universidade Federal do Pampa - UNIPAMPA. 
ABSTRACT: O presente estudo, de cunho qualitativo, é um recorte da tese de doutorado da autora a qual propôs um novo modelo de Webquest voltado ao ensino de línguas por meio de um sistema interativo de autoria - a ferramenta Elo Cloud. Os resultados aqui apresentados voltam-se ao papel reflexivo de futuros professores de língua inglesa quanto ao uso das Webquests Interativas e Adaptáveis nas práticas de ensino e aprendizagem de línguas. As reflexões feitas a partir da fala dos professores em formação demonstraram que as Webquests Interativas e Adaptáveis são potencializadoras no processo de aprendizagem de línguas por fornecerem conteúdos interativos e dinâmicos que focam no aprendizado da língua inglesa.

KEYWORDS: webquest; teachers; language teaching.

\section{Introdução}

O crescente número de trabalhos voltados ao estudo das influências das tecnologias no processo de ensino e aprendizagem de línguas (BUZATTO, 2001; CARELLI, 2003; PAIVA, 2008; VETROMILLE-CASTRO, 2008; LEFFA, 2009) nos levam cada vez mais a crer que o uso das tecnologias já é uma realidade presente nas práticas de ensino. Este argumento não aponta para o fato de que o uso desses artefatos tecnológicos resolvem os problemas encontrados nas aulas de línguas, mas devemos pensar que a sociedade atual está mudando as formas de interação e comunicação e, consequentemente, as formas de ensinar e aprender uma língua. Nesse sentido, não podemos esquecer que as tecnologias foram criadas em função da língua e existem para servi-la (LEFFA, 2009). Além disso, Coutinho e Bottentuit Junior (2008) comentam que as TIC geram várias potencialidades, gerando ambientes ricos e promotores de experiências pedagógicas a que as escolas não podem ficar alheias. O uso das tecnologias na busca por informaçóes e conhecimento deve fazer com que o professor de línguas reflita sobre os processos de ensino e aprendizagem, uma vez que neles se insere a importância das informações na construção coletiva do saber. Aceitar a influência das novas tecnologias e da internet no processo de ensino e aprendizagem é essencial para que as práticas de ensino de línguas se desenvolvam de forma eficaz e significativa. No passado, preparávamos os alunos através de leituras em livros, atividades em folha impressa e por meio de informações expostas no quadro negro. Hoje, contamos também com o apoio de uma lousa interativa, uma leitura online do conteúdo estudado, jogos e atividades motivadoras advindas de uma rede que contempla o uso de imagens, cores e personificação. Em outras palavras, contamos com a multimodalidade que potencializa as práticas no 
contexto de ensino de línguas. Levando isso em consideração, o professor que está inserido em um contexto de cibercultura (LEVY, 1999) precisa se aproximar das práticas de ensino que envolvem essa realidade, bem como compreender e refletir criticamente sobre o papel das tecnologias no âmbito social e educacional.

O trabalho aqui apresentado é um recorte dos resultados da tese $\mathrm{e}^{3} \mathrm{da}$ autora, o qual foca de maneira específica a opinião de futuros professores de língua no que tange ao uso de Webquests Interativas e Adaptativas no ensino e aprendizagem da língua inglesa. Criada em 1995, pelo professor da San Diego State University, Bernie Dodge, a metodologia vem ganhando destaque no Brasil e no mundo. Dodge (1995) e outros autores (MILTON, A.J \& DOWNEY, 2001; CARVALHO, A, 2002; MARCO LUZÓN, 2002; BOSWELL, 2003; MARCH, 2003; LAMB, 2004; LABORDA, 2009) têm publicado artigos relacionados ao uso de Webquests no meio educacional na intenção de investigar os benefícios e limitações da metodologia nos processos de aprendizagem. No Brasil, Jarbas Novelino Barato, professor da Universidade de São Paulo (USP) e um dos criadores da Escola do Futuro, disseminou o estudo sobre a metodologia. No cenário brasileiro, cabe citar também como pioneiros no assunto Ribeiro e Souza (2002), Mercado e Viana (2003) e Bottentuit Junior (2009).

$\mathrm{Na}$ intenção de apresentar ao leitor um breve retrospecto da metodologia Webquest, este trabalho está dividido em 3 seçôes, além desta introdução e das consideraçôes finais: (1) Webquest: do passado ao presente; (2) O que é uma Webquest Interativa e Adaptável voltada ao ensino de línguas? e (3) Reflexões de professores em formação sobre o uso de Webquests Interativas e Adaptáveis nas aulas de língua inglesa.

\section{Webquest: do passado ao presente}

A metodologia Webquest surgiu em 1995 e foi desenvolvida pelo professor Bernie Dodge, da Universidade da Califórnia, o qual divulga e desenvolve suas ideias no site Webquest.org. Neste site, Dodge e seu seguidor Tom March têm criado um ambiente de discussão entre vários países sobre a metodologia, bem como um repositório de Webquests sobre os mais diversos assuntos da área do conhecimento. Desde então, Dodge (1995)

\footnotetext{
${ }^{3}$ Tese intitulada $O$ desenvolvimento e a implementação de uma Webquest Interativa e Adaptativa destinada ao ensino de línguas.
} 
e outros autores (MILTON \& DOWNEY, 2001; CARVALHO, 2002; MARCO LUZÓN, 2002; BOSWELL, 2003; MARCH, 2003; LAMB, 2004; LABORDA, 2009) têm publicado artigos relacionados ao uso de Webquests no meio educacional na intenção de investigar os benefícios e limitações da metodologia no processo educacional. De acordo com Dodge (1995), uma Webquest é uma atividade investigativa, em que as informações com que os alunos interagem provêm da Internet. Uma definição mais detalhada acerca das Webquests é apresentada por March (2003) a qual diz que: Uma verdadeira Webquest é uma estrutura de aprendizagem em andaimes que usa hiperligações (links) para recursos essenciais disponíveis na Web e constitui-se numa tarefa autêntica que motiva a investigação dos alunos acerca de uma questão aberta, do desenvolvimento da especialidade individual e a participação no processo de grupo que transforma a nova informação adquirida numa compreensão mais sofisticada. As melhores Webquests inspiram os alunos a ver relações temáticas mais ricas, contribuem para o mundo real da aprendizagem e refletem nos seus próprios processos metacognitivos. Buscamos também outra definição das Webquests, por Jarbas Novelino Barato, professor da Universidade de São Paulo (USP) e um dos criadores da Escola do Futuro6, que disseminou o estudo da metodologia: É um modo de como organizar informações para facilitar a aprendizagem a partir de processos investigativos. Não tem nada a ver com programa de computador, tela de computador ou particularidades da informática. Tem a ver com a aprendizagem humana. A Webquest foi criada pelo educador Bernie Dodge, preocupado com o interesse e a motivação por aprender, que propôs um modelo para organizar informações dentro dessa coisa que no Brasil chamamos de "Internet", mas que ele trata como "espaço web". Dodge (2002), como muitos educadores, vê na Internet uma fonte imensa de informaçôes atualizadas e disponíveis em uma linguagem do tipo "aqui e agora”. Mas a Internet é uma das coisas mais desorganizadas do mundo. Buscar uma informação não é tão fácil quanto parece, mesmo com sites de busca. É sempre uma aventura em que a gente nunca sabe onde vai chegar (SENAC, 2003, online). Após, surgiram artigos (MERCADO \& VIANA, 2003; RIBEIRO \& SOUZA Jr., 2002; SENAC SP, 2003; COUTO, 2004; ABAR \& BARBOSA, 2008; COSTA, 2008; BOTTENTUIT JUNIOR, 2009) que tratam do assunto Webquest. Em 2008, Abar e Barbosa, professoras da Pontifícia Universidade Católica de São Paulo (PUC-SP), contribuíram de forma significativa para o entendimento das Webquests, 
com a publicação do livro "Webquest: um desafio para o professor". Além disso, mencionamos a tese de João Bottentuit Junior (2010) que averiguou a criação, avaliação e dinamização de um portal de Webquests em Língua Portuguesa. A literatura evidencia que a utilização de Webquests nas ciências exatas, por exemplo, é cada vez mais comum. O estudo realizado por Silva (2006) aponta os benefícios que o uso de Webquests fornece aos alunos em termos de cooperação e pesquisa no aprendizado da matemática. $\mathrm{O}$ autor demonstrou em sua dissertação, intitulada A Geometria Espacial no ensino médio a partir da atividade Webquest: análise de experiência, que a metodologia enriquece o ensino da geometria espacial de forma significativa. Moran (1995) vai ao encontro desse estudo ao enfatizar que resolver uma Webquest é um processo de aprendizagem interessante, porque envolve pesquisa e leitura, interação, colaboração e criação de um novo produto a partir do material disponível na internet. No site da Escola do Futuro, pioneira no assunto Webquest no Brasil, encontramos uma lista com os objetivos educacionais de uma Webquest: 1) modernizar modos de fazer educação; 2) garantir acesso a informações autênticas e atualizadas; 3) promover a aprendizagem cooperativa; 4) desenvolver habilidades cognitivas; 5) traduzir ativamente informações, ao invés de apenas reproduzi-las; 6) incentivar a criatividade; 7) favorecer o trabalho de autoria dos professores; 8) favorecer o compartilhar de saberes pedagógicos. Não podemos deixar de mencionar também o estudo de Rocha (2007), que analisou as concepções de pesquisa que abarcam o trabalho de professores quando propõem atividades por meio da metodologia Webquest. Os resultados desse estudo apontaram, a partir do discurso dos docentes, que há um grande interesse acerca da importância da pesquisa no contexto educacional, porém, há dificuldades em pôr em prática açôes que busquem ampliar as questóes relacionadas à investigação. No que diz respeito aos estudos já realizados com Webquests e ensino de línguas, citamos o estudo de Silva (2008), o qual identificou até que ponto a Webquest pode ser considerada um elemento a ser inserido no contexto de ensino e aprendizagem de línguas na promoção de habilidades comunicativas. Já o estudo de Bohn (2009) apresentou a Webquest e o uso de Podcast como ferramentas que podem ser utilizadas na promoção da aprendizagem de línguas. Em 2013, temos a pesquisa de Silva, Bruz \& Brahim, a qual teve como objetivo relatar uma experiência por meio das Webquests em um curso de graduação de Secretariado Executivo Trilíngue, na intenção de corroborar a ideia de que as ferramentas tecnológicas potencializam o aprendizado de uma língua estrangeira. Ainda no que se 
refere ao ensino de línguas, mencionamos aqui as ideias de Torres (2005), as quais enfatizam que a definição de Webquest para o ensino e aprendizagem de línguas estrangeiras vai um pouco além da definição de Dodge. Segundo a autora, além de ser uma atividade que prioriza o uso orientado da internet na construção coletiva do saber por meio do trabalho colaborativo, uma Webquest de língua estrangeira deve proporcionar aos alunos a possibilidade de aprender e praticar a língua-alvo colocando em prática as habilidades linguísticas. Dessa forma, Torres (2005, p. 3), conclui que além da potencialidade que apresenta como metodologia de aprendizagem, uma Webquest designada para o ensino e aprendizagem de uma língua deve ser construída levando em consideração alguns princípios, dos quais destacamos aqui os objetivos linguísticos e não linguísticos e a criação de um produto que implique no uso comunicativo da língua.

Ton Koenraad, professor da Universidade de Utrecht, na Holanda, criou um site dedicado a Webquests que focam no ensino de línguas estrangeiras a partir de um projeto realizado na universidade. Este projeto, o qual possui o nome de TalenQuest (em inglês, LanguageQuest) tem como principal objetivo o desenvolvimento de Webquests que contemplem o uso da língua estrangeira. Além disso, o projeto enfatiza que uma LanguageQuest deva priorizar o uso flexível e criativo da língua através de uma tarefa que envolva os alunos e desenvolva habilidades linguísticas e de análise crítica. De modo geral, Koenraad (2003) define uma LanguageQuest como uma Webquest com foco na aprendizagem de línguas estrangeiras. O conceito parece ser inovador, uma vez que adapta a ideia de Webquest já designada por Dodge, porém com um olhar especial ao ensino e aprendizagem de línguas de modo a estabelecer a diferença entre uma Webquest educativa e uma Webquest destinada ao ensino de línguas estrangeiras. Segundo Koenraad (2003), uma LanguageQuest deve ir além da definição de Dodge, uma vez que aprender uma segunda língua envolve importantes elementos que não são levados em consideração ao construir uma Webquest: o input, o qual é uma pré-condição para a aprendizagem segundo Krashen (1982); o significado, que só será efetivo se as atividades relacionarem o input fornecido com os processos de analisar, sintetizar e induzir informações; foco na forma, o qual se direciona a prática dos aspectos formais da língua como, por exemplo, as estruturas sintáticas e morfológicas; produção, que diz respeito à tarefa que desencadeará o processo de desenvolvimento do produto final, o qual deverá desenvolver a transformação da informação em conhecimento 
a partir da negociação de significado; e, finalmente, o uso de estratégias, que está ligado ao uso das estratégias utilizadas pelos alunos na área da recepção e produção da língua. No artigo de Bottentuit Junior (2009), em que o autor analisou 483 Webquests em língua portuguesa disponíveis online, entre Julho e Outubro de 2007, identificou-se que a fatia mais representativa no que tange ao número de Webquests disponíveis é a de Ciências da Natureza, com $23 \%$ dos exemplares. Este número vai ao encontro da pesquisa realizada por Bottentuit Junior e Santos (2014), seguido pelas Webquests que foram concebidas e trabalhadas de forma multidisciplinar, que contaram 13\% dos exemplares. As outras áreas identificadas foram: História (10\%), Inglês (8\%), Biologia (8\%), Matemática (7\%) entre outras. Ainda na mesma pesquisa, verificou-se que a maioria dos trabalhos e pesquisas realizadas ocorre em nível escolar (84\%), seguidos do nível superior (4\%) e cursos de formação profissional (2\%). Em uma entrevista dada ao site da revista online Education World, Dodge (2000) comenta que a metodologia Webquest começou em 1995 em um curso de capacitação para professores, oferecido por Bernie Dodge, na Universidade de Columbia, Estados Unidos. Em uma das aulas, Dodge queria apresentar aos professores algumas informações sobre o software Arquetype ${ }^{4}$ porém alguns imprevistos aconteceram. Dodge não dispunha de nenhum equipamento que pudesse mostrar o software de forma ilustrativa. Além disso, o programa Arquetype não estava instalado nos computadores para uso dos alunos/docentes. O que fazer perante os alunos que ali esperavam pela aula? Dodge se deu conta de que o único recurso de que ele dispunha naquele momento era a internet. Desse modo, ele propôs uma tarefa na qual os alunos, em grupos, deveriam organizar um documento dirigido ao diretor de uma escola, recomendando o uso do software Arquetype. Para a realização da tarefa, os alunos deveriam levar em consideração a seguinte orientação: parte das informações deveria ser retirada de recursos disponíveis da internet. Cabe ressaltar que esses recursos já haviam sido escolhidos por Dodge previamente. Ademais, os alunos deveriam se dividir em três grupos e cada grupo deveria escrever um relatório final e apresentar para a turma. O resultado final foi além das expectativas de Dodge. Os alunos se engajaram na tarefa devido a sua organização e a tarefa levou-os a um comprometimento e motivação para montar o produto final -

\footnotetext{
${ }^{4}$ Software que gerencia documentos e recupera arquivos e informações de uma forma mais eficiente.
} 
o relatório. Abar e Barbosa (2008) vão ao encontro dessa ideia e argumentam que: A tarefa proposta, a organização da atividade e a dinâmica do trabalho levam os alunos a um comprometimento especial com o resultado e com a construção do próprio conhecimento, tornando cada um responsável, especialista e colaborador de forma ativa, para a obtenção do resultado. Esta experiência mostrou a Dodge que uma nova maneira de ensino e aprendizagem em alto nível através dos conteúdos oferecidos pela internet começava a florescer - a metodologia Webquest. Foi a partir dessa aula, então, que a metodologia passou a chamar a atenção de Dodge e de muitos pesquisadores (MARCH, 2000; CARVALHO, 2003; BARATO, 2004; SILVA, 2006; ABAR \& BARBOSA, 2008; BOTTENTUIT JUNIOR, 2010) das mais diversas áreas.

Após a aula que levou Dodge à criação da Webquest, o professor publicou um pequeno artigo sobre o assunto definindo a metodologia como uma atividade investigativa, em que alguma ou todas as informaçōes com que os alunos interagem provêm da Web. Após a definição do conceito, é publicada em abril de 1995 a primeira Webquest intitulada Searching for China, a qual tinha como objetivo fazer com que os alunos entrassem numa aventura sobre a China na intenção de buscar informações sobre seus aspectos culturais, sociais e econômicos. Por ser uma metodologia rica na qual a pesquisa é desenvolvida dentro de um espaço organizado, as Webquests buscam aproveitar, de forma significativa, as informações disponíveis na Web em prol de uma aprendizagem com foco na colaboração e na construção coletiva do conhecimento. Segundo Barato (2004), o interesse pela proposta de Dodge conquistou educadores do mundo todo e em três anos o número de Webquests publicadas na rede chegou à casa dos milhares. Em linhas gerais, o trabalho com Webquest envolve aspectos bastante importantes e que devem ser levados em consideração durante o desenvolvimento e implementação. Dodge (1999) argumenta que os objetivos das Webquests envolvem a construção do conhecimento por meio do trabalho colaborativo, o desenvolvimento das habilidades cognitivas, a transformação das informações em conhecimento, além da promoção da criatividade e do trabalho de autoria dos professores. Ainda segundo o autor, as Webquests podem ser divididas em duas categorias: curtas e longas. Uma Webquest curta pode ser realizada em uma, duas ou três aulas, e seu objetivo é fazer com que o aluno entre em contato com um número grande de informações e tente integrá-las a fim de compreendê-las. Já Webquests 
longas têm duração de uma semana a um mês e objetivam refinar e polir o conhecimento dos alunos em relação a um tema específico. De maneira geral, o objetivo de uma Webquest é fazer com que os alunos se engajem ativamente numa determinada atividade com o intuito de construir conhecimento a partir das informações existentes na internet e da cooperação entre os pares.

\section{0 que é uma Webquest Interativa e Adaptável voltada ao ensino de línguas?}

\subsection{Webquest Interativa}

Uma Webquest Interativa destinada ao ensino de línguas é aquela que não só viabiliza a transformação das informações provenientes da Web em conhecimento, mas também amplia e/ou reforça aspectos relacionados à língua alvo por meio de desafios interativos e comunicativos. Esses desafios ampliam e expandem o aprendizado de línguas por meio de interações distribuídas entre os sujeitos e os recursos existentes no sistema de atividade. Concluímos que uma Webquest Interativa com foco no ensino e aprendizagem de línguas deverá ser desenvolvida a partir de quatro aspectos que a difere de uma Webquest comum: 1. O momento Pré-tarefa; 2. A importância de input linguístico; 3. A tarefa como um ato comunicativo; 4. A utilização de desafios linguísticos/WebExercises menores, com foco na língua-alvo e que estejam relacionados com a tarefa maior. $\mathrm{O}$ primeiro aspecto, o momento Pré-tarefa, tem como objetivo apresentar ao aluno: (1) o desenho da lição; (2) a estrutura de participação; (3) input sobre o tema a ser abordado e (4) o conhecimento de mundo dos alunos diante do tema da Webquest. O desenho da lição e a estrutura de participação (ELLIS, 2003) estão voltados para as explicações preliminares de como a atividade ocorrerá a partir de orientaçóes sobre o papel de cada um durante o processo de aprendizagem. Explicaçóes sobre a metodologia Webquest, incluindo seus componentes, são bem-vindas neste momento. Os itens 3 e 4 estão direcionados ao uso da língua por meio de atividades curtas (WILLIS, 1996) que ativem o conhecimento de mundo dos alunos e exponha-os a um input relacionado com o tema da Webquest. O segundo aspecto, o input linguístico, parece ser um tanto simples, pois ao se criar Webquests voltadas à língua inglesa, por exemplo, estas serão elaboradas com textos e orientaçôes em inglês e isto já faz com que elas tenham 
um input. Entretanto, nos referimos aqui à importância de um input compreensível (KRASHEN, 1993), de modo que o aluno perceba a língua por meio de expressões linguísticas e extralinguísticas ligadas a um contexto específico. Em uma Webquest Interativa voltada ao ensino de línguas, o input compreensível deverá aparecer de forma contextualizada em todos os componentes. $\mathrm{O}$ terceiro aspecto, a tarefa como um ato comunicativo, deverá ser entendido a partir de dois atos comunicativos. O primeiro está relacionado à relevância de se propor tarefas autênticas, comunicativas, executáveis e que estejam relacionadas à realidade dos alunos. Já o segundo ato comunicativo diz respeito à maneira como o discente chegará à tarefa, ou seja, em uma Webquest Interativa voltada ao aprendizado de línguas a tarefa é compreendida por meio de um desafio linguístico, que pode ser entendido como um ato comunicativo. Pensemos na Webquest "Back to the future" como exemplo. Para que os participantes chegassem à tarefa, eles deveriam, primeiramente, ler uma carta do personagem McFly, a qual era apresentada de forma enigmática. Foi somente pelo uso da língua, ao completar a carta, que os alunos compreenderam a tarefa maior da Webquest. Assim, as Webquests Interativas voltadas ao ensino de línguas devem proporcionar aos alunos mais oportunidades de uso do idioma por meio de seus componentes, neste caso, a tarefa. O quarto e último aspecto, a utilização de desafios interativos linguísticos, é relevante pelos seguintes motivos: o primeiro diz respeito ao fato de que estes desafios podem ser compreendidos como microtarefas comunicativas, que fazem parte de uma macro tarefa (a tarefa maior da Webquest) e que desenvolvem habilidades específicas de uso da língua, as quais auxiliam na elaboração do produto final. Esses desafios devem ser elaborados a partir da atenção voltada ao significado, mas nada impede que o foco na forma também seja praticado. Tudo dependerá dos objetivos da Webquest e do professor ao elaborá-la ou reutilizá-la. O segundo motivo refere-se ao fato de que esses micro desafios devem ser realizados de maneira conjunta entre os sujeitos envolvidos, de modo que se estabeleçam relações entre os alunos, o professor e o artefato não humano (Webquest). Nesse sentido, ressaltamos que a interatividade é fator primordial na elaboração dessas atividades. Na Webquest "Back to the future", por exemplo, a ênfase na interatividade deu-se a partir dos desafios que, ao serem elaborados por

${ }^{5}$ http://www.elo.pro.br/cloud/aluno/atividade.php?id=355\&limpa_score=1 
meio da ferramenta ELO Cloud ${ }^{6}$, proporcionaram aos alunos feedbacks imediatos a partir da interação simulada. Os quatro elementos citados acima fazem da Webquest Interativa voltada ao ensino de línguas uma metodologia de ensino capaz de agregar elementos importantes relacionados aos aspectos linguísticos. Como mencionamos anteriormente, a nossa proposta visa ampliar o que já fora proposto por Dodge, de modo a beneficiar alunos e professores que estão envolvidos com o ensino e a aprendizagem de línguas.

\subsection{Webquest Adaptável}

Uma Webquest Adaptável é aquela que poderá ser reutilizada e adaptada pelo usuário de acordo com as suas necessidades. $\mathrm{O}$ conceito de adaptabilidade é compreendido como a capacidade do sistema em se adaptar de acordo com as preferências e limitações dos aprendizes que estão inseridos em um determinado contexto educacional. No que tange à elaboração de Webquests, estas são tradicionalmente desenvolvidas por professores e hospedadas em sites para que outros docentes utilizem-nas. A reutilização dessas Webquests é feita "por inteiro", em que o professor não pode escolher apenas o que lhe interessa. Muitas vezes, as Webquests chamam a atenção dos docentes, mas quando estes analisam o conteúdo e os sites disponíveis, percebem que os seus alunos não estariam preparados para participar daquele tipo de atividade, ou já teriam visto o conteúdo apresentado. Nesse sentido, entendemos que as Webquests ainda se encontram "engessadas" e "estáticas" sem que o usuário possa utilizá-la de forma mais maleável. Atualmente, com as discussões que tratam dos Recursos Educacionais Abertos, a importância do compartilhamento e da possibilidade do usuário tornar-se mais ativo em relação ao conteúdo da Web, cabe a reflexão sobre a possibilidade de haver Webquests mais "vivas" e "maleáveis", as quais os professores possam adaptar e readaptar para o seu contexto de ensino. A reusabilidade (WILEY, 2001) é um fator relevante no que se refere às Webquests elaboradas, mas é também importante pensar que, além de reusá-las os professores podem ainda adaptálas. A ferramenta de autoria ELO Cloud possibilitou esta discussão, uma vez que fornece ao professor autor módulos que podem ser reutilizados e adaptados. Segundo Leffa (2013), os módulos em uma atividade no ELO Cloud são pequenos e moldáveis, podendo ser compartilhados, usados, reusados e, principalmente, adaptados pelo docente. Ainda segundo o

${ }^{6}$ http://www.elo.pro.br/cloud/index.php 
autor, a questão da adaptabilidade está relacionada com a possibilidade do ELO Cloud de expandir a colaboração por meio da implementação dos quatro 'R's: reusar, redistribuir, revisar e remixar (HILTON et al, 2010). Ao desenvolvermos uma Webquest Interativa com foco no aprendizado de línguas por meio do ELO Cloud, chegamos à conclusão de que estávamos, também, desenvolvendo uma Webquest "viva", que poderia ser adaptada por outros professores, levando assim, a uma Webquest Adaptável. Isso acontece porque o ELO Cloud possibilita a montagem de atividades a partir de componentes separados, os módulos. O termo "separado" é utilizado aqui para mostrar a diferença entre uma Webquest estática, criada por meio de outras ferramentas, em que os componentes são colocados juntos na mesma página, formando um bloco monolítico que é acessado por meio de links. Já o ELO Cloud possibilita que o usuário crie uma atividade "por inteiro", mas não monolítica, na medida em que pode ser adaptada por meio dos módulos que são criados separadamente. Como mencionado na tese ${ }^{7}$ foi possível compreender algumas das formas de adaptação de Webquests envolvendo cores, uso de imagens, conteúdo, entre outros elementos. A adaptação de uma Webquest faz com que esta se mantenha "viva" e renasça a cada nova versão. A Webquest "Back to the future", por exemplo, foi elaborada para ser implementada em uma turma de nível pré-intermediário, mas um professor de nível avançado, por exemplo, poderia readaptá-la e transformá-la em uma Webquest mais complexa, e um docente com uma turma de nível básico poderia simplificá-la. Teríamos, assim, três Webquests com o mesmo tema, mas com níveis diferentes. O conceito de Webquest Adaptável surge como uma nova perspectiva no que tange ao desenvolvimento e utilização de Webquests no âmbito educacional. Como vimos, é preciso que a ferramenta de autoria de elaboração de Webquests tenha a capacidade de fazer com que a Webquest torne-se maleável e adaptável.

\section{Reflexões de professores em formação sobre o uso de Webquests Interativas e Adaptáveis nas aulas de língua inglesa.}

Como abordado anteriormente na Introdução deste trabalho, o objetivo geral deste artigo é tecer reflexões sobre a opinião de futuros professores de língua inglesa sobre a utilização de Webquests Interativas e Adaptáveis nas aulas de línguas.

${ }^{7}$ Disponível em: http://antares.ucpel.tche.br/poslet/dissertacoes/Doutorado/2014/. 
A proposta metodológica está ancorada na abordagem qualitativa por compreendermos que essa abordagem se preocupa com o "contexto e com o processo ao invés de atentar simplesmente para os resultados" (BOGDAN \& BIKLEN, 1994, p. 49). Além disso, esse tipo de pesquisa prima a importância da descrição dos dados possibilitando, assim, os estudos de fenômenos que envolvem os seres humanos e suas relaçôes sociais as quais são estabelecidas em diferentes ambientes.

Para a coleta de dados, utilizamos mais de um instrumento de pesquisa, pois acreditamos que dessa forma a coleta torna-se mais abrangente e fornece uma maior diversidade de informações proporcionando uma compreensão mais profunda do fenômeno estudado. Neste artigo, abordaremos apenas o instrumento questionário, uma vez que o foco é a opinião dos professores em formação sobre o uso da ferramenta.

A Webquest interativa e Adaptável "Back to the Future" utilizada na pesquisa foi desenvolvida entre janeiro e fevereiro de 2014. Sua aplicação em sala de aula e coleta de dados realizou-se no mês de abril de 2014, durante quatro dias de aula da disciplina de Língua Inglesa VI, num total de doze horas/aula. Cabe salientar que, previamente, no mês de março, foi realizado um projeto piloto com uma turma de Língua Inglesa V. Para que o leitor tenha uma ideia geral da estrutura da Webquest "Back to the future", apresentamos abaixo a tela inicial, a qual traz a Introdução da Webquest. Nesta Introdução, os alunos são convidados a fazer uma viagem ao passado, presente e futuro de forma que a língua inglesa seja praticada em todos os momentos.

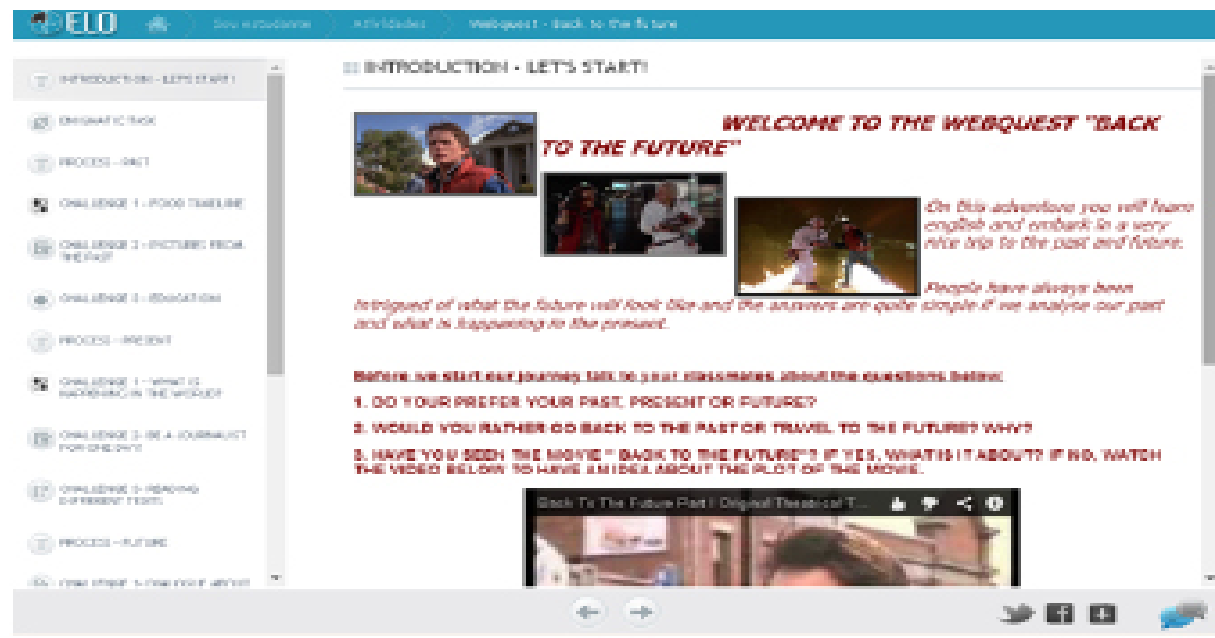

Figura 1: Introdução da Webquest Back to the future Fonte: ELO Cloud 
A pesquisa realizada foi desenvolvida em uma turma do sexto semestre do Curso de Letras de uma universidade da cidade de Pelotas. Optou-se por desenvolver uma pesquisa com Webquest no ensino superior, uma vez que a utilização de Webquests no contexto universitário ainda é pouco explorada. Além disso, acreditamos que as opiniōes de futuros professores de língua inglesa acerca da utilização das Webquests contribui de forma significativa para os avanços da pesquisa em torno da criação e implementação de Webquests voltadas ao ensino de línguas.

Salientamos que trataremos os sujeitos desta pesquisa como estudantes a partir da sigla $\mathrm{E}$ (Estudante) e o número relativo ao quantitativo da amostra $(\mathrm{E} 1, \mathrm{E} 2, . .$.$) na intenção de preservar o anonimato.$

Quadro 1: Faixa etária dos sujeitos envolvidos

\begin{tabular}{|c|c|}
\hline Estudante & Idade \\
\hline Estudante 1 (E1) & 44 anos \\
\hline Estudante 2 (E2) & 25 anos \\
\hline Estudante 3 (E3) & 52 anos \\
\hline Estudante 4 (E4) & 32 anos \\
\hline Estudante 5 (E5) & 29 anos \\
\hline Estudante 6 (E6) & 38 anos \\
\hline Estudante 7 (E7) & 24 anos \\
\hline Estudante 8 (E8) & 28 anos \\
\hline Estudante 9 (E9) & 20 anos \\
\hline Estudante 10 (E10) & 22 anos \\
\hline Estudante 11(E11) & 24 anos \\
\hline Estudante 12 (E12) & 23 anos \\
\hline
\end{tabular}

Fonte: Autora, 2015.

Apresentaremos, a seguir, a fala de futuros professores em formação sobre o ensino e aprendizagem de línguas por meio de uma Webquest Interativa e Adaptável. Para que possamos discutir cada ponto, apresentamos abaixo os questionamentos feitos aos professores em formação e em seguida discussão em cima de suas opiniōes e considerações acerca da ferramenta. 
- Você acha que o uso da Webquest "Back to the future" ${ }^{8}$ tornou a aprendizagem da língua inglesa mais interessante? Sim? Não? Justifique.

- A Webquest Back to the future trouxe algum conhecimento novo em relação aos conteúdos e/ou língua inglesa? Justifique.

- Qual a sua opinião acerca dos minidesafios/minitarefas desenvolvidas em cada etapa do PROCESSO? Eles ajudaram no desenvolvimento da tarefa final?

- Qual a importância da ferramenta ELO Cloud?

- Há benefícios para o aprendizado de línguas a partir da Webquest Back to the future? Sim? Não? Justifique.

- Quais os possíveis problemas e limitações que você, sendo futuro professor de línguas, vê na Webquest Back to the future?

- Você, sendo futuro professor de línguas, utilizaria Webquests desenvolvidas a partir da ferramenta ELO Cloud? Sim? Não? Justifique.

No que diz respeito aos primeiros questionamentos foi possível verificar os benefícios da Webquest Interativa e Adaptável , uma vez que os futuros docentes apontaram questôes referentes não só ao aprendizado da língua alvo, mas também no que tange aos aspectos interativos da metodologia.

Sim. É possível, porque faz com que nós se interesse mais pela língua inglesa, enquanto que o método tradicional não incentiva muito, principalmente para mim que sei pouco da língua e nesse método gostei da maneira como é abordado o ensino. (E2)

Sim. Algo dinâmico e interativo sempre chama mais a atenção do que aulas tradicionais. (E7)

Acho que o uso da Webquest, retomando termos, sendo interativo, relembrando uma história, ouvindo música, enfim, acrescentou algo bastante produtivo. (E10)

Sim. Tivemos um maior envolvimento com a língua inglesa. (E5)

Eu tenho certeza que o uso da Webquest foi de essencial ajuda, pois nos ajudou a ver de uma maneira diferente o aprendizado da língua. $\mathrm{E}$ também tivemos contato com o professor e o computador em sala de aula

\footnotetext{
${ }^{8}$ Disponível em: http://www.elo.pro.br/cloud/aluno/atividade.php?id=355\&limpa_ score $=1$.
} 
o que culminou numa aprendizagem interessantíssima. (E8)

Sim. Ficou muito mais interessante, pois é uma forma lúdica e motivacional para o aprendizado de língua inglesa. (E11)

Sim. Até mesmo para mim que não gosto muito de tecnologia. Mas aprendi muito mais dessa forma diferente e divertida. (E2)

Pelas declarações dos alunos, constata-se a motivação e o interesse pela língua inglesa a partir da metodologia. Os depoimentos ressaltam a possibilidade de um maior envolvimento com a língua e, desse modo, entendemos que o ensino dos tempos verbais da língua inglesa, por meio de um trabalho contextualizado como o estabelecido pela Webquest "Back to the future", é percebido como algo positivo, dinâmico e interativo. O ensino dos tempos verbais, por meio de um trabalho contextualizado a partir de desafios que estão ligados a um objetivo final, aprofundou e/ou revisou os seus próprios conhecimentos, bem como proporcionou uma compreensão maior acerca do uso dos tempos verbais. Este argumento pode ser também verificado nos depoimentos abaixo:

Em questão de conteúdo, apesar de não gostar de inglês, mas gosto de jogos. Adorei o jogo da memória e as respostas. Trazem um conhecimento além. (E12)

Conheci e adquiri palavras novas. (E9)

Nos mostrou algumas expressões que até então não conhecíamos e nos instigou a usar habilidades para podermos resolver os exercícios. (E7) Contribuiu para um maior desenvolvimento da escrita e da leitura. (E4) Retomou bastante alguns termos, principalmente no que diz respeito ao futuro. (E8)

Nos depoimentos acima, o grupo pesquisado utiliza expressões como "conhecimento além”, "palavras novas", "habilidades", "desenvolvimento" e "retomar termos", que levam à ideia do "aprender uma segunda língua” por meio de uma Webquest.

$\mathrm{Na}$ intenção de ir além das observações feitas acerca dos desafios e a importância desses e das ferramentas utilizadas para que o objetivo fosse atingido, perguntamos aos discentes a opinião deles sobre os desafios desenvolvidos em cada etapa do Processo e se eles ajudaram na elaboração da tarefa final: 
Sim, ajudaram. Porque através dos desafios e tarefas tínhamos mais conhecimento acerca do assunto que escolhemos falar. (E1)

Ajudaram muito, pois chamou a atenção para palavras e temas novos. (E2)

Sim, pois as pequenas tarefas deram base para a tarefa final. (E3)

Com certeza! A partir destes desafios pudemos embasar nosso trabalho final, tirando dali tanto a gramática quanto o conteúdo em si. Também nos possibilitou ter acesso a uma ferramenta fundamental: nosso esforço. (E4)

Ajudam. Até diria que são fundamentais, pois dali se tirou a ideia final. (E6)

Confesso que no início me senti confusa, digamos. Não sabia ao certo como proceder. Mas após o resultado os desafios ajudaram bastante. (E10)

Ajudaram. A cada atividade desenvolvida foi possível aprender um pouco mais. (E8)

Os aspectos mencionados pelos alunos, em negrito, revelam o importante papel dos desafios para a construção do conhecimento em uma Webquest Interativa e Adaptável destinada ao ensino de línguas. Além disso, os desafios foram elaborados com base na importância da ampliação e da expansão do conhecimento, o que também foi verificado pelos participantes: "foi possível aprender um pouco mais", "tínhamos mais conhecimento". Cabe ressaltar aqui que, no início, os desafios causaram uma tensão ou confusão, como dito pelo aluno E10, mas acreditamos que esta tensão foi positiva, uma vez que auxiliou para que a aprendizagem ocorresse de forma expansiva e ampliada.

No que diz respeito ao uso do ELO Cloud para a elaboração da Webquest, os alunos mostraram-se bastante atraídos pelo fato de ela facilitar a aprendizagem:

Acho que o ELO possibilita toda a interatividade: conteúdo, conhecimento e mundo virtual. Uma ferramenta que possibilita conhecimento em línguas. (E10)

Eu achei interessante o ELO. Qualquer pessoa independente da idade pode gostar de fazer e aprender inglês. (E4)

É simples e fácil de usar. (E6) 
O ELO foi uma experiência sensacional, pois nos permite realizar tarefas de forma simples, embora seja uma ferramenta sofisticada. Eu espero poder usar mais vezes. (E2)

O ELO é uma forma agradável de aprender a língua. (E11)

Por meio da fala dos alunos, verificamos que o ELO Cloud é uma ferramenta potencializadora no que tange ao ensino e aprendizagem de línguas, por agregar vários aspectos, como a questão da interatividade, a facilidade de uso e a elaboração de atividades independente da idade, além do fato de tornar o aprendizado de línguas mais agradável. Chamamos a atenção para a fala do aluno E2, que sabe da sofisticação da ferramenta, mas comenta que ao mesmo tempo permite que o aprendiz realize tarefas de forma simples. A interatividade comentada pelo aluno E10 é argumentada por Leffa (2006), quando o autor inclui quatro aspectos fundamentais em um sistema de autoria interativo: (1) o conteúdo; (2) a maneira como este será apresentado; (3) os tipos de feedback; e (4) as ajudas por meio de pistas e dicas. Nesse sentido, a Webquest "Back to the future" agregou esses quatro aspectos durante a criação e manteve as características fundamentais de uma Webquest educacional, transformando-se, assim, em uma Webquest Interativa e Adaptável. O resultado, como pode ser visto, foi bastante produtivo e enriquecedor. Ainda acerca da ferramenta, os alunos mencionaram que:

O ELO tem em si o feedback quase instantâneo e permite que possamos realizá-las quantas vezes for necessárias. (E1)

Ele é simples e claro. Tá tudo ali nele mesmo, não preciso abrir outra janela de site. (E3)

Amplia o aprendizado pelas atividades porque em qualquer momento utilizamos ferramentas que nos ajudam com a língua. (E8)

Ele possibilita o uso virtual, pesquisas, ícones como o dicionário que servem de ajuda durante o processo. (E6)

Ele traz mais recursos e aperfeiçoa a nossa capacidade de interação com a atividade. (E12)

A partir do exposto pelos alunos, percebemos que a elaboração da Webquest "Back to the future" por meio da ferramenta ELO Cloud fez toda a diferença em termos de ampliação da aprendizagem. O feedback instantâneo, 
o fato de podermos acoplar os sites dentro do ELO, o uso de ferramentas como os dicionários on-line, por exemplo, transformam a Webquest de língua em uma Webquest Interativa e Adaptável. A fala do aluno E12 remetenos ainda à possibilidade de ampliação da Cognição Distribuída, já que há uma interação maior entre aluno e a atividade on-line.

Ao serem questionados acerca do uso de Webquests por meio da ferramenta ELO Cloud em suas práticas futuras como professores de línguas, os alunos demonstraram querer usar por todas as possibilidades que foram vistas durante o processo.

Sim. Eu usaria e já estou usando em uma disciplina que escolhi para fazer neste semestre. (E10)

Sabendo como desenvolver, sabendo da realidade do meu público alvo que fosse usar utilizaria sim. Há muitos recursos. (E1)

Sim. Porque achei a ferramenta uma excelente maneira de trabalhar a língua. (E8)

Sim. Se eu achar que meus alunos estão preparados para lidar com uma ferramenta virtual. (E5)

Sim. Infelizmente dependemos dos recursos que as escolas onde estivermos forneça, mas eu usaria se fosse possível. (E3)

Sim. Com certeza meus alunos iriam gostar por ser uma atividade parecida com as que eles têm no computador (E7)

Os alunos mostram-se otimistas quanto à prática com Webquests, mas sabem que o uso depende do público, dos objetivos e da estrutura escolar na qual estão ou estarão inseridos no futuro. A aluna E6, sobre as limitações, comenta "eu não vejo limitaçôes ou problemas porque os alunos estão a cada dia mais ligados em computadores". Salientamos aqui que os discentes vivem sim na era digital, mas a questão do conteúdo ainda é fator primordial, como salienta Demo (2009), isto é, tem que haver uma pedagogia por trás da atividade interativa para que a construção do conhecimento de fato ocorra.

\section{Considerações finais}

O processo de inserção das Tecnologias de Informação e Comunicação (TIC) como ferramentas mediadoras em atividades direcionadas ao ensino e à aprendizagem de idiomas já faz parte da realidade de muitos indivíduos que buscam o aprendizado de línguas, sejam estas maternas ou estrangeiras, por 
meio de aplicativos, jogos, redes sociais e objetos de aprendizagem. A partir desta realidade, parece que não podemos ignorar a questão de como reusar e adaptar esses para uma aprendizagem de língua mais efetiva, abordando as teorias que estão por trás dessas atividades que parecem motivar e aguçar a curiosidade de muitos.

No que tange ao posicionamento de futuros professores de línguas quanto aos benefícios e limitações das Webquests Interativas e Adaptáveis, foi possível constatar que os alunos tiveram um maior contato com a língua-alvo por meio dos desafios ligados à tarefa maior. Além disso, eles argumentaram ter praticado as quatro habilidades da língua de maneira interativa e comunicativa, por meio dos desafios, e relacionaram o sucesso do produto final com a prática da língua por meio dessas atividades. Dessa forma, entendemos que os desafios linguísticos foram essenciais no que diz respeito à prática das habilidades, à importância de input compreensível e à exposição à língua-alvo. No que concerne às limitações, percebemos que estas estavam ligadas ao nível de conhecimento linguístico dos alunos, uma vez que os sujeitos com baixo nível de proficiência tiveram problemas maiores referentes às instruções, por exemplo. A turma-alvo era bastante heterogênea, não somente em relação à idade, mas também quanto ao nível linguístico. Acreditamos que essa heterogeneidade linguística poderá limitar um pouco o aprendizado da língua-alvo por meio de Webquests Interativas e Adaptativas, uma vez que os aprendizes não conseguirão tirar proveito significativo da atividade. A Webquest "Back to the future" foi desenvolvida para ser implementada com discentes de curso superior em nível pré-intermediário, mas esta nomenclatura não condizia com a realidade da turma. Assim, pensamos que em grupos mais homogêneos, em se tratando do nível linguístico, as Webquests Interativas e Adaptáveis voltadas ao ensino de línguas poderão potencializar de maneira mais efetiva a aprendizagem. Perante os depoimentos dos alunos que serão futuros professores de línguas, constatamos que uma Webquest Interativa poderá vir a ser uma ferramenta que enriquece o trabalho com a língua estudada, por oferecer ao aluno uma atividade que envolve a pesquisa, a interação entre os pares, professor e computador e a exposição à língua-alvo por meio de desafios dinâmicos e interativos, os quais são essenciais para o desenvolvimento do produto final. Uma limitação apontada pelos futuros professores foi o fato de que muitas vezes as escolas não possuem estrutura para esse tipo de atividade, já que a mesma depende do acesso à internet. 
Este trabalho corroborou a hipótese de que o uso de Webquests adaptadas para o ensino de línguas eleva o índice de satisfação dos alunos/futuros professores de língua inglesa na execução da atividade, proporcionando condiçóes mais favoráveis para a aprendizagem. Dessa forma, a nossa proposta volta-se para a exploração de aspectos linguísticos por meio de desafios interativos durante o processo de construção do conhecimento em Webquests, transformando-as, assim em Webquests Interativas destinadas ao aprendizado de línguas. Este estudo ainda tomou como base a importância da evolução da ciência por meio das transformações. Acreditamos que, ao transformarmos uma Webquest comum em uma Webquest Interativa e Adaptável voltada ao ensino de línguas, estamos contribuindo com o avanço da linguística aplicada no que tange aos estudos sobre Webquest e o seu papel na promoção do ensino e aprendizagem de línguas.

\section{Referências}

ABAR, C. A. A. P.; BARBOSA, L. M. WebQuest, um desafio para o professor: uma solução inteligente para o uso da Internet. São Paulo: Avercamp, 2008.

BARATO, J. N. (2004). El Alma de las WebQuest. In: Revista Electrónica Quaderns Digitals (Espanha). Disponível em: www.quadernsdigitals.net. Acesso em: 10 out. 2013.

BLOOM, B. S. Taxonomia dos objetivos educacionais. Domínio Cognitivo. Porto Alegre: Ed. Globo, 1972.

BOGDAN, R. C.; BIKLEN, San K. Investigação qualitativa em educação. Porto, Portugal: Porto Editora, 1994. 335p.

BOHN.V.C.R. O uso da Webquest e Podcast na criação de material didático para o ensino de língua estrangeira. In: Anais do SILEL, v. 1, Uberlândia, EDUFU, 2009. BOSWELL, N. A WebQuest for "because of winn-dixie." In: Reading Online, v. 6, n. 6, 2003.

BOTTENTUIT. J. J.B. Análise de WebQuests em língua portuguesa disponíveis on-line: aspectos relativos à qualidade dos componentes e da usabilidade. In: Revista Brasileira de Estudos Pedagógicos, v. 90, n. 224, Brasília, pp. 102-121, jan./abr. 2009. BOTtentuit. J. J.B. Concepção, Avaliação e Dinamização de um Portal Educacional de WebQuests em Lingua Portuguesa. 2010. Tese (Doutorado) Universidade do Minho, Portugal, 2010.

BOTTENTUIT. J. J. B.; SANTOS. C. G. (no prelo) Revisão sistemática da literatura das dissertaçôes sobre a metodologia Webquest. 
BRAHIM A. C. S. N.; BRUZ I. M.; SILVA E. M. O. O uso da metodologia Webquest no ensino de língua inglesa no curso de secretariado executivo trilíngue: um relato de experiência. In Revista X, v. 1, 2013.

BUZATO, Marcelo El Khouri. O Letramento Eletrônico e o Uso do Computador no Ensino de Lingua Estrangeira: Contribuiçôes para a Formação de Professores. Disponível em: http://www.bibliotecadigital.unicamp.br/ document/?code=vtls000219553. 2001.

CARELLI, I. M. Estudar on-line: análise de um curso para professores de inglês na perspectiva da teoria da atividade. 2003. Tese (Doutorado) - Pontifícia Universidade Católica, São Paulo, 2003.

CARVALHO, A. A. A. WebQuest: evolução e reflexo na formação e na investigação em Portugal. In: COSTA, F. A. PERALTA, H \& VISEU, S. (Orgs.) As TIC em Portugal: concepções e práticas. Porto: Porto Editora, 2008.

CARVALHO, A. A. A. WebQuest: desafio colaborativo para professores e para alunos. In: Elo, Revista do Centro de Formação Francisco de Holanda Guimarães (Portugal), n. 10, pp. 142-150, 2002.

COELHO, L. C. A.; SILVA, L. R. C. (2008). Análise de Webquests: a problematização como critério de elaboração. Disponível em: <http://www.portalwebquest.net/ referencias. htm>. Acesso em: 27 dez. 2013.

COSTA, I. M. S. A WebQuest na Aula de Matemática: um estudo de caso com alunos do $10^{\circ}$ ano de escolaridade. 2008. Dissertação (Mestrado) Braga: Universidade do Minho, Instituto de Educação e Psicologia, 2008.

COUTO, M. S. A Eficácia da WebQuest no Tema Nós e o Universo - usando uma Metodologia numa Perspectiva CTS: um estudo de caso com alunos do $8^{\circ}$ ano de escolaridade. 2004. Dissertação (Mestrado) Braga: Universidade do Minho, 2004. CORTELLA M. S. O naufrágio de muitos internautas. Folha de São Paulo, 6 de julho de 2000.

DANIELS, H. Vygotsky e a Pedagogia. São Paulo: Edições Loyola, 2003.

DEMO, P. Educação hoje: "novas" tecnologias, pressões e oportunidades. São Paulo: Atlas, 2009.

DODGE, B. Some Thoughts about WebQuests. 1995. Disponível em: http:// WebQuest.s dsu.edu/about_WebQuests.html. Acesso em: 10 jul. 2013.

DODGE, B. Creating a Rubric for a Given Task. 1999a. Disponível em: http:// projects. edtech.sandi.net/staffdev/tpss99/rubrics/rubrics.html. Acesso em: 10 fev. 2009.

DODGE, B. Process Checklist. 1999b. Disponível em: http://projects.edtech. sandi. net/staff dev/ tpss99/processchecker.html. Acesso em: 10 set. 2013. 
DODGE, B. WebQuest Taskonomy: A Taxonomy of Tasks. 2002. Disponível em: http://e dweb.sdsu.edu/WebQuest/taskonomy.html. Acesso em: 10 jun. 2013.

DODGE, B. Motivational Aspects of WebQuest Design. In: CRAWFORD, C. et al. (Eds.), Proceedings of Society for Information Technology and Teacher Education International Conference, Chesapeake, VA: AACE, p. 1737-1739, 2003, p. 17371739.

ELLIS, R. Task-based language teaching and learning. Oxford: Oxford University Press, 2003.

KOENRAAD, A. L. M.; WESTHOFF, G. J. (2003) Can you tell a Language Quest when you see one? Design critera for TalenQuests. In: Conference of the European Association for 77 Computer Assisted Language Learning: EUROCALL 2003. Limerick: Universidade de Limerick, Irlanda, 3-6 de setembro, 2003.

KRASHEN, S. Principles and Practice in Second Language Acquisition. New York, NY: Pergamon, 1982.

LABORDA, J. G. Using webquests for oral communication in English as a foreign language for Tourism Studies. In: Educational Technology \& Society, v. 12, n. 1, p. 258-270, 2009.

LAMB, A. Key words in instruction. WebQuests. In: School Library Media Activities Monthly, v. 21, n. 2, p. 38-40, 2004.

LARSEN, Steen. Aspectos sociais e psicológicos das Tecnologias Educacionais. In: Jornada Catarinense de Tecnologias Educacionais, v. 2, 2000, Florianópolis.

LATOUR, B. Technology is society made durable. In: LAW, J. (Ed.). A Sociology of Monsters: Essays on Power, Technology and Domination, London: Routledge, -p. $103-131,1991$.

LEFFA, V. J. Metodologia do ensino de línguas. In: BOHN, H. I.; VANDRESEN, P. Tópicos em linguística aplicada: $\mathrm{O}$ ensino de línguas estrangeiras. Florianópolis: Ed. da UFSC, p. 211-236, 1988.

LEFFA, V. J. Aprendizagem mediada por computador à luz da Teoria da Atividade. In: Pesquisa em Linguística Aplicada. Pelotas: Educat, 2006.

LEFFA, V. J. Malhação na sala de aula: o uso do exercício no ensino de línguas. In: Revista Brasileira de Linguistica Aplicada, Belo Horizonte, v. 8, n. 1, p. 139-158, 2008.

LEFFA, V. J. Se mudo o mundo muda: ensino de línguas sob a perspectiva do emergentismo. In: Calidoscópio, v. 7, n. 1, p. 24-29, jan./abr. 2009.

LEFFA, V. J. Aprendizagem mediada por computador à luz da teoria da atividade. In: Calidoscópio, v. 3, n. 1, p. 21-30, jan./abr. 2005. 
LEFFA, V. J. Creating activities from adaptive learning objects. In: WorldCall, Glasgow, 2013.

LEFFA, V. J. Sistemas de autoria para a produção de objetos de aprendizagem. In: BRAGA, Junia (Org.). Integrando tecnologias no ensino de Inglês nos anos finais do Ensino Fundamental. São Paulo: Ediçōes SM, p. 174-191, 2012.

LÉVY, P. Cibercultura. Rio de Janeiro: Ed. 34, 1999.

LUZÓN MARCO, M. J. Internet Content-Based Activities for English for Specific Purposes. In: Forum, v. 40, n. 3, p. 20-25, 2002.

MARCH, T. Why WebQuests?, an introduction. 1998. Disponível em: http://www. tomm arch.com/writings/intro_wq.php. Acesso em: 9 fev. 2009.

MARCH, T. The Learning Power of WebQuests. In: Educational Leadership, v. 61, n. 4, 2003.

MARCH, T. Tips on choosing and assessing WebQuests. 2000. Disponível em: http:// www. infotoday.com/MMSchools/oct00/march.htm. Acesso em: 9 fev. 2009.

MERCADO, L. P. L.; VIANA, M. A. P. Formação de professores para aprendizagem na internet: Webquest como investigação orientada. In: XVI Encontro de Pesquisa Educacional do Norte e Nordeste, 2003, Aracajú - SE. Anais do EPENN do XVI - Encontro de Pesquisa Educacional do Norte e Nordeste, Aracajú - SE, v. 1. p. 501-501, 2003.

MILTON, A. J. \& DOWNEY, P. WebQuest: Using internet resources for cooperative inquiry. In: Social Education, v. 65, n. 3, p. 144-146, 2001.

MORAN, J.M. Novas tecnologias e o re-encantamento do mundo. In: Tecnologia Educacional, Rio de Janeiro, v. 23, n. 126, set./out., 1995, p. 24-26. Disponível em: http://www.eca.usp.br/prof/moran/novtec.htm. Acesso em: 20 mar. 2011.

MORAN, J.M. Internet no ensino universitário: pesquisa e comunicação na sala de aula. In: Interface: comunicação, saúde e educação, v. 2, n. 3, p.125-132, 1998. PAIVA V. M. Reconfigurando a sala de aula em ambientes virtuais de aprendizagem. In: BARCELOS, A. M. F. (Org.) Linguística Aplicada: reflexôes sobre ensino e aprendizagem de língua materna e língua estrangeira. Campinas: Pontes, p. 119139, 2011.

PAIVA V. M. O uso da tecnologia no ensino de linguas estrangeiras: breve retrospectiva histórica. 2008b. Disponível em: http://www.veramenezes. com/techist.pdf. Acesso em: 12 abr. 2014.

PEREZ, TORRES. I. A model of Webquest for teaching and learning a L2. Universidade de Granada, Eurocall, 2005.

PRABHU.N.S. Second Language Pedagogy. New York, Toronto: Oxford University Press, 1987. 
REA BRASIL. Recursos Educacionais Abertos. 2011. Disponível em: http://www. rea.net .br/site/. Acesso em: 12 mar. 2014.

RIBEIRO, G. S. N.; SOUSA JR, R. T. Webquest: Protótipo de um Ambiente de Aprendizagem Colaborativa a Distância. In: Revista Brasileira de Aprendizagem Aberta e a Distância, 2002. Disponível em: http://www.abed. org.br/congresso 2001/55.zip. Acesso em: 14 jul. 2011.

ROCHA, L. R. A Concepção de Pesquisa no Cotidiano Escolar: Possibilidades de Utilização da Metodologia WebQuest na Educação pela Pesquisa. 2007. Dissertação (Mestrado) - Universidade Federal do Paraná, Curitiba, 2007.

SENAC/SP. O que é. 2003. Disponível em: <http://webquest.sp.senac.br/textos / oque >. Acesso em: 15 abr. 2013.

SILVA, M. B. A Geometria espacial no ensino médio a partir da actividade de WebQuest: análise de uma experiência. Dissertação (Mestrado) - Pontifícia Universidade Católica de São Paulo, São Paulo, 2006.

SILVA, E. M. O. A Webquest na internet: o novo material didático. Monografia de conclusão do curso de especialização em Ensino de Línguas Estrangeiras Modernas da UTFPR, Curitiba, 2008.

VETROMILLE-CASTRO, R. Considerações sobre grupos em ambientes virtuais de aprendizagem como sistemas complexos. Revista Brasileira de Linguística Aplicada, v. 8, n. 1, p. 211-234, 2008.

VYGOTSKY, L.S. Pensamento e linguagem. São Paulo: Martins Fontes, 1989.

VYGOTSKY, L.S. A Formação Social da Mente: O Desenvolvimento dos Processos Psicológicos Superiores. São Paulo: Martins Fontes, 1998.

WILLIS, J. A Framework for task-based learning. Harlow: Longman, 1996.

WILLIS, D., \& WILLIS J. Task-based language learning. In R. CARTER, \& D. NUNAN (Eds.), The Cambridge Guide to Teaching English to Speakers of Other Languages. Cambridge, UK: Cambridge University Press, 2001.

WILLIS, D., \& WILLIS J. Doing task-based teaching. New York: Oxford University Press, 2007. 
